\title{
Development and implementation of a screening method to categorise the greenhouse gas mitigation potential of 91 landfills
}

Fredenslund, Anders Michael; Mønster, Jacob; Kjeldsen, Peter; Scheutz, Charlotte

Published in:

Waste Management

Link to article, DOI:

10.1016/j.wasman.2018.03.005

Publication date:

2019

Document Version

Peer reviewed version

Link back to DTU Orbit

Citation (APA):

Fredenslund, A. M., Mønster, J., Kjeldsen, P., \& Scheutz, C. (2019). Development and implementation of a screening method to categorise the greenhouse gas mitigation potential of 91 landfills. Waste Management, 87, 915-923. https://doi.org/10.1016/j.wasman.2018.03.005

\section{General rights}

Copyright and moral rights for the publications made accessible in the public portal are retained by the authors and/or other copyright owners and it is a condition of accessing publications that users recognise and abide by the legal requirements associated with these rights.

- Users may download and print one copy of any publication from the public portal for the purpose of private study or research.

- You may not further distribute the material or use it for any profit-making activity or commercial gain

- You may freely distribute the URL identifying the publication in the public portal 
1 Development and implementation of a screening method to categorise the greenhouse gas mitigation potential of 91 landfills

3

Anders M. Fredenslund ${ }^{\mathrm{a}}$, Jacob Mønster ${ }^{\mathrm{b}}$, Peter Kjeldsen ${ }^{\mathrm{a}}$, Charlotte Scheutz ${ }^{\mathrm{a}}$

5

6 a Department of Environmental Engineering, Technical University of Denmark, Bygningstorvet, Building 115, DK-

$7 \quad 2800$ Kongens Lyngby, Denmark

$8 \quad{ }^{\mathrm{b}}$ FORCE Technology, Park Allé 345, 2605 Brøndby, Denmark

9

10

E-mail addresses:

11

Corresponding author: Anders M. Fredenslund: $\underline{\operatorname{amfr} @ e n v . d t u . d k}$

12

Author: Jacob Mønster: jmn@force.dk

13

Author: Peter Kjeldsen: pekj@env.dtu.dk

14

Author: Charlotte Scheutz: chas@env.dtu.dk

15

\section{HIGHLIGHTS}

17

- A cost-effective screening method was developed to estimate landfill methane emissions

- The method combined measured methane plume concentrations and dispersion modelling

- 91 landfills were categorised with regards to methane emissions

- The method was found to be sensitive to variations in model input parameters

- Modelled emission rates differed from tracer gas dispersion measurements

- The method was, at best, semi-quantitative, but nevertheless useful for landfill emission categorisation

ABSTRACT

A cost-effective screening method for assessing methane emissions was developed and employed to categorise 91 older

Danish landfills into three categories defined by the magnitude of their emissions. The overall aim was to assess

whether these landfills were relevant or irrelevant with respect to methane emission mitigation through the construction of biocovers. The method was based on downwind methane concentration measurements, using a van-mounted cavity ring-down spectrometer combined with inverse dispersion modelling to estimate whole-site methane emission rates. 
1 This method was found to be less precise than the more labour-intensive tracer gas dispersion method, and therefore

2 cannot be recommended if a high degree of precision is required. However it is useful if a less accurate examination is

3 sufficient. A sensitivity analysis showed the dispersion model used to be highly sensitive to variations in input

4 parameters. Of the 91 landfills in the survey, 25 were found to be relevant for biocover construction when the methane 5 emission threshold was set at $2 \mathrm{~kg} \mathrm{CH}_{4} \mathrm{~h}^{-1}$. 


\section{Introduction}

Methane emissions from landfills are a major source of greenhouse gas produced by the waste sector on a global scale (Bogner et al., 2008). Landfill methane is primarily produced by the anaerobic digestion of organic matter in landfilled waste, which continues for decades after the waste has been deposited (Lou and Nair, 2009).

As part of a national effort to reduce greenhouse gas emissions, the Danish government has allocated approximately $€ 24$ million for the establishment of biocovers in order to reduce methane emissions from a number of Danish landfills before 2020 (Danish Environmental Protection Agency, 2016a). Biocovers are systems in which the cover of a landfill is designed or modified to optimise biological methane oxidation, thus reducing methane leakage (Scheutz et al., 2014; 2011; 2009).

Organic household waste was landfilled in Denmark until 1997, thus there are a number of old, closed landfills in the country that are potential sources of methane release. At these sites, the establishment of biocovers to mitigate methane emissions could be relevant as an alternative to gas collection and utilisation options, which often are not technically or economically feasible at older landfills with decreasing gas generation rates. To focus available funds on constructing biocovers in locations where sizeable methane emissions occur, approximately 4,000 landfill sites were initially assessed following a desktop screening of procedure-based historical information (including disposed waste amounts, waste fractions, reported gas investigations etc.). Previous studies found that methane emissions can be much lower than anticipated from information on waste composition, age, amounts etc. (Scheutz et al., 2011). In addition, only sparse information relevant to methane generation prediction was available for many of the landfills. Therefore to finalise the desk-top screening process and determine appropriate sites for biocover implementation, it was decided to develop and apply a simple, cost-effective method to estimate total methane emissions based on fast methane concentration measurements combined with modelling, where a trade-off in the form of lower accuracy was accepted compared to more precise, but more costly measurement options.

The purpose of this study was to develop and apply a cost-effective measurement protocol to categorise methane emissions from 91 landfills, combining downwind methane concentration recordings with simple modelling assuming Gaussian plume distribution.

\section{Materials and methods}

2.1 Desk-top screening procedure for identification of landfills with potential methane emissions 
In Denmark there are about 4000 closed landfill sites registered. Since landfilling of organic household waste ended in 1997, it was assessed that in spite of their age, landfills suitable for methane mitigation measures through the construction of biocovers were to be found among older sites. Out of 4000 older landfills, 183 landfills were chosen as potential candidates. Landfill sites for which no information was available, sites located in EU Natura 2000-protected areas and sites with current activities not allowing the installation of a biocover system were disregarded. Likewise, landfills that were either too old (landfilling ceased prior to 1965) or too small (area less than $5000 \mathrm{~m}^{2}$ ) were eliminated from consideration. Further analysis of available information on the remaining sites regarding present area use, waste composition, modelling of gas generation and leachate composition reduced the number of candidates for biocover implementation from 183 to 91 landfills.

Since this study concerned mostly older landfills, information on the age of waste, waste types etc. was generally limited. The 91 landfills included in this study were distributed geographically across Denmark (Fig. 3) in both rural and urban environments. The sites had been closed down between 1965 and 2002, according to the records obtained. Furthermore, for a number of the landfills, their operational periods were unknown.

Each landfill contained between 12,000 and 2,550,000 tonnes of waste, according to records. At some sites, there had been an analysis of landfill gas composition and relatively high methane concentrations had been noted (up to approximately $60 \%$ vol.).

\subsection{Inverse dispersion modelling method}

To estimate total methane emission rates from the landfills included in this study, an inverse dispersion model (IDM) method was used based on downwind measurements of methane concentrations combined with plume dispersion modelling. The IDM method is a modification of the tracer gas dispersion (TGD) method, which relies on the controlled release of a tracer gas combined with downwind measurements of the target gas (methane in this case) and the tracer gas (Mønster et al., 2015; 2014). The TGD method is the method recommended by the Danish Environmental Protection Agency for providing accurate measurements of methane emissions from landfills in relation to the implementation of biocovers (Danish Environmental Protection Agency, 2016b). The IDM method is less labourintensive and therefore quicker to use and less costly in comparison to the TGD method. However, the IDM method is less accurate - at best semi-quantitative - whereas the TGD is a quantitative method where emissions can be determined with a fairly high accuracy (a difference of less than $15 \%$ ), when performed under optimal measuring conditions (Mønster et al., 2014). Methane emission rates determined using the IDM method are referred to as estimated emissions, whereas emission rates determined using the TGD method are referred to as quantified emissions. 
1 The accuracy of the IDM method was investigated by comparing the methane emission rates obtained by application of this method to simultaneous measurements of methane emissions using the TGD method. In addition, a sensitivity analysis was performed to examine the effect of varying model parameters on estimated methane emissions.

In the IDM method, methane emissions at the individual landfills were estimated using a simple Gaussian plume model (Fig. 1). The concentration of gas downwind from an emitting source can be expressed as:

$C(x, y, z)=\frac{Q}{U} \frac{1}{2 \pi \sigma_{y} \sigma_{z}} e^{\left(\frac{-y^{2}}{2 \sigma_{y}^{2}}\right)}\left[e^{\left(\frac{-(z-H)^{2}}{2 \sigma_{z}^{2}}\right)}+e^{\left(\frac{-(z+H)^{2}}{2 \sigma_{z}^{2}}\right)}\right]$

where $\mathrm{C}(\mathrm{x}, \mathrm{y}, \mathrm{z})$ is the concentration of the emitted gas $\left(\mathrm{g} \mathrm{m}^{-3}\right)$ above background concentration at a given point in the downwind plume, $\mathrm{Q}$ is the emission $\left(\mathrm{g} \mathrm{s}^{-1}\right), \mathrm{U}$ is the wind speed $\left(\mathrm{m} \mathrm{s}^{-1}\right), \mathrm{H}$ is the effective emission height $(\mathrm{m}), \mathrm{z}(\mathrm{m})$ and $\mathrm{y}(\mathrm{m})$ are the vertical and horizontal distances from the measurement point to the centre of the plume, and $\mathrm{x}(\mathrm{m})$ is the distance from the source to the measurement point (Fig. 1). The parameters $\sigma_{\mathrm{y}}(\mathrm{m})$ and $\sigma_{\mathrm{z}}(\mathrm{m})$ are the vertical and horizontal dispersion coefficients respectively. At each site, the emission point was assumed to be the centre of the landfill, since information on the spatial distribution of surface emissions at the sites was not available (Fig. 1). Under optimal measuring conditions, methane concentrations are measured far enough downwind of the landfill to consider the landfill as a point source in the landscape. The model includes ground reflection since emission occurs at ground level and the downwind plume therefore cannot disperse downwards. To estimate the methane emission $Q$ from the measured downwind concentrations, the Gaussian plume model described by equation 1 was applied by using the peak methane concentration measured in the downwind plume. Since methane emitting from a landfill can be considered to occur at ground level, $\mathrm{H}$ was assumed to be 0 . Considering $\mathrm{y}=0$ and $\mathrm{H}=0$, the calculation of $\mathrm{Q}$ can thereby be derived from Eq. 1 as follows:

$Q=C(x, 0, z) \cdot U \cdot \pi \sigma_{y} \sigma_{z} e^{\left(\frac{z^{2}}{2 \sigma^{2}}\right)}$

The dispersion coefficients $\left(\sigma_{\mathrm{y}}\right.$ and $\left.\sigma_{\mathrm{z}}\right)$ describe how the emitted gas is dispersed in the atmosphere. Based on Pasquill-Gifford atmospheric stability classes, dispersion coefficients were calculated using equations provided by Briggs (1973) (Table 1). The stability classes are named A to F, where A is very unstable, B is moderately unstable, C is slightly unstable, D is neutral, E is slightly stable and F is stable (De Visscher, 2014). A further description of the Pasquill-Gifford stability classes and Briggs equations for determining the dispersion coefficients can be found in De Visscher (2014). The emission of gas from the landfill was estimated by measuring downwind methane concentrations and using atmospheric conditions measured at local weather stations to estimate the dispersion coefficients. 
To determine the peak methane concentration, $\mathrm{C}(\mathrm{x}, 0, \mathrm{z})$, a Gaussian fit was applied to the measured methane

plume transect, obtained by plotting the measured methane concentrations as a function of time, using Origin Pro 2016 data analysis software (OriginLab Corporation, Massachusetts, USA). Fig. 2 shows a Gaussian fit of measured downwind methane concentrations used to determine peak height (maximum methane concentration above background)

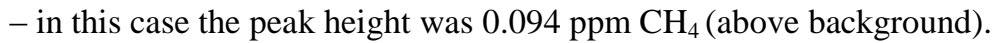

\subsection{Measuring protocol}

The following measurement protocol was applied to estimate landfill methane emissions.

Step 1: Screening of methane concentrations downwind of the landfill and in the surrounding area

Each measurement started with a methane concentration screening (the measurement of ambient methane concentrations approximately 2 metres from ground level) to evaluate the location of elevated methane concentrations downwind of each landfill and assess whether any other methane sources were present in the area that could affect the measurements. At each landfill, both upwind and downwind measurements were performed on drivable roads near the site where possible, preferably by circling the landfill while measuring. The locations and boundaries of each of the landfills were known from historical maps.

\section{Step 2: Downwind methane plume traversing}

Where elevated methane concentrations (concentrations above background) were observed downwind from the landfill, four traverses of the methane plume were performed. This was done by driving at a constant and relatively slow speed of approximately $20-30 \mathrm{~km} \mathrm{~h}^{-1}$. If no plume was observed, the emission was reported as below detection limit. The lowest detectable emission depends not only on the detection limit of the analytical instrument, but is the combined result of weather conditions, measuring distance and the analytical instrument. Thus the detection limit is specific to the conditions during each field campaign. Here the detection limit was estimated using the approach suggested by Delre et al. (2017). The minimum detectable emission rate was estimated using the inverse Gaussian plume model and sitespecific parameters for weather and measuring distance. The smallest detectable downwind peak plume concentration C_min $(\mathrm{x}, 0,2)$ was estimated by considering a minimum signal-to-noise ratio equal to 3 detected on the measurement day. The average minimum detectable emission rate considering all measurement campaigns was $0.15 \mathrm{~kg} \mathrm{CH}_{4} \mathrm{~h}^{-1}$. Step 3: Modelling of methane emissions

For each methane plume traverse, the peak methane concentration was determined using the Gaussian fit, and a methane emission rate estimated using Eq. 2. The measuring distance was defined as the distance from the centre of the landfill to the point where the maximum methane concentration was recorded. The estimated methane emission rate for 
each landfill was the average value calculated based on the four plume traverses. Weather data, including wind speed, were obtained from the online service www.weatherunderground.com where historical data from local weather stations can be accessed. These data are typically recorded at the nearest airport.

In most cases, Pasquill-Gifford stability class D was used in the dispersion calculations since most of the measurements were performed in overcast weather conditions.

Step 4: Categorisation of landfills based on IDM estimates

Based on the IDM estimated methane emission rates, the landfills were categorised into three emission categories:

- $\quad$ low emission $\left(<2 \mathrm{~kg} \mathrm{CH}_{4} \mathrm{~h}^{-1}\right)$ : not relevant for a biocover

- medium emission (2-6 $\left.\mathrm{kg} \mathrm{CH}_{4} \mathrm{~h}^{-1}\right)$ : potentially relevant for a biocover

- $\quad$ high emission $\left(>6 \mathrm{~kg} \mathrm{CH}_{4} \mathrm{~h}^{-1}\right)$ : relevant for a biocover

If elevated methane concentrations (a methane concentration less than a signal-to-noise ratio of 3) were not observed downwind from a landfill, the landfill was categorised as "low emission". The numerical emission thresholds listed above were set in agreement with the Danish Environmental Protection Agency, the government department overseeing the biocover initiative. Implementation of a biocover system at a landfill with an emission of less than $2 \mathrm{~kg}$ $\mathrm{CH}_{4} \mathrm{~h}^{-1}$ is not considered cost-effective and landfills categorised in the "low emission" group were essentially removed from consideration for biocover implementation. At landfills with an emission above $6 \mathrm{~kg} \mathrm{CH}_{4} \mathrm{~h}^{-1}$ biocovers are considered a cost-effective mitigation technology in comparison to other mitigation actions (Scheutz et al., 2014; Tværministeriel arbejdsgruppe, 2013). The landfill category with emissions between 2 and $6 \mathrm{~kg} \mathrm{CH}_{4} \mathrm{~h}^{-1}$ was considered an intermediate category where further measurements would be required before a final conclusion could be drawn on whether a biocover system should be installed. Furthermore, these sites would only be considered relevant if relatively cheap biocover solutions could be implemented, otherwise the cost per reduced $\mathrm{CO}_{2}$ equivalent would be too high.

\subsection{Analytical equipment for plume concentration measurements}

Downwind plume methane concentrations were measured using a mobile analytical platform consisting of a high-precision methane analyser and a global navigation satellite system (GNSS) receiver mounted on a vehicle. Methane concentrations were measured using a cavity ring-down spectrometer (G2203, Picarro Inc., USA), installed on a vehicle, with gas in the atmosphere pumped into the analyser from an intake placed on the roof of the car approximately $2 \mathrm{~m}$ above ground level. The measurement frequency of the instrument was approximately $2 \mathrm{~Hz}$ and the 
precision level of the methane was $0.48 \mathrm{ppb}$, which enabled small variations in the atmospheric concentrations to be detected.

A GNSS system was used to log the position of the measurements (R330 GNSS receiver and A43 antenna, Hemisphere, Canada), while a weather station mounted on the vehicle was used to log temperature and atmospheric pressure (All-In-One weather sensor, model 102780, Climatronics, USA).

\subsection{Accuracy and sensitivity assessment}

\subsubsection{Comparison of simultaneous emission estimates using inverse dispersion modelling and tracer gas}

\section{dispersion measurements}

To assess the accuracy of the IDM method, methane emission rates obtained by IDM were compared to methane emission rates obtained by application of the TGD method. In total, 24 datasets were used where methane emissions had been quantified using TGD. Based on methane plume data, methane emission rates were estimated using IDM and compared to the emission rates measured by TGD. Five of the datasets used were from tracer gas release measurements from the 91 landfills included in this study, where tracer gas was released and calculations of methane emissions performed for each plume traverse using both IDM and TGD methods. The remaining 19 landfill measurements were performed by the authors in previous studies, including the landfill measurements described in Mønster et al. (2015). The methane emission calculations for these historical datasets were performed using data from the first four transects of downwind plumes following the protocol described in Section 2.2.

The TGD method has been applied in previous studies to quantify fugitive methane emissions from landfills as well as other sources, such as wastewater treatment plants (Foster-Wittig et al., 2015; Goldsmith et al., 2012; Mønster et al., 2015; Yoshida et al., 2014). The TGD method is recommended by the Danish Environmental Protection Agency for the provision of accurate measurements of methane emissions from landfills with regard to the implementation of biocovers (Danish Environmental Protection Agency, 2016b). The TGD method relies on the controlled release of a gaseous tracer combined with downwind measurements of the target gas (methane in this case) and the tracer gas (Mønster et al., 2015; 2014).

The TGD method is based on the assumption that a tracer gas released at an emission source, in this case a landfill, will disperse into the atmosphere in the same way as methane emitted from the landfill. Assuming that the wind direction is defined, conditions in the air above the landfill are sufficiently combined for the methane and tracer gas to be fully mixed, with the tracer gas release and methane emission being constant. The methane emission rate $\left(\mathrm{E}_{\mathrm{gas}}\right)$ can 
be calculated as a function of the ratio of the integrated cross-plume concentration of methane emitted into the integrated cross-plume concentration of the tracer gas according to Eq. 3 (Mønster et al., 2015):

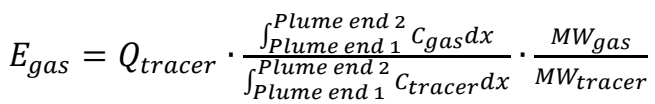

where $\mathrm{Q}_{\text {tracer }}$ is the release rate of the tracer gas $\left(\mathrm{kg} \mathrm{h}^{-1}\right), \mathrm{C}_{\mathrm{gas}}$ and $\mathrm{C}_{\text {tracer }}$ are concentrations of methane and the tracer (ppbv) above background level, $\mathrm{MW}_{\text {gas }}$ and $\mathrm{MW}_{\text {tracer }}$ are the molecular weights of methane and the tracer gas, and $\mathrm{x}$ is the distance across the plume.

In order to place tracer gas in the most accurate location to simulate methane emissions from a site, an initial methane concentration screening was performed on drivable roads at the site, which provided a qualitative assessment of the emission pattern. From this screening, one or more locations were chosen, from where the tracer gas was released. An adequate simulation of the emission pattern of the site, releasing a carefully placed tracer, will result in a close match of the methane and tracer gas plumes measured downwind from the site. If improper source simulation was observed, the configuration of the tracer gas release was changed prior to emission quantification. The described procedure was followed at all 24 sites where the TGD was applied. The method is described in more detail in Mønster et al. (2014), which also includes an assessment of the method's measurement accuracy.

The gas tracer used for the measurements in this study was acetylene $\left(\mathrm{C}_{2} \mathrm{H}_{2}\right)$, and 21-L gas bottles each containing $3.2 \mathrm{~kg}$ acetylene were used for continuous tracer release. The release flows from the bottles were controlled using calibrated flow meters and regulators (Sho-Rate, Brooks Instruments, Holland).

Downwind methane and acetylene plume concentrations were measured using the same analytical instrument as described in Section 2.4, which recorded acetylene concentrations with a precision of $0.4 \mathrm{ppb}$.

\subsubsection{Influence of modelling parameters on emission estimates using inverse dispersion modelling}

The IDM method relies on a Gaussian dispersion model that depends on dispersion coefficients, which vary according to weather conditions and terrain type. Three of the sites of the landfills surveyed in this study were chosen for the performance of sensitivity tests regarding changes to modelling parameters, representing three cases where the distance between landfill and plume traverse as well as observed emission rates varied, but the choice was otherwise random:

- Landfill 1: measurement of a landfill with a low emission, where measurements were taken a relatively short distance from the landfill (distance: $300 \mathrm{~m}$ )

- Landfill 2: measurement of a landfill with a high emission, where measurements were taken a relatively short distance from the landfill (distance: $140 \mathrm{~m}$ ) 
- Landfill 3: measurement of a landfill with a high emission, where measurements were taken a relatively long distance from the landfill (distance: $2200 \mathrm{~m}$ ).

To test the sensitivity of the IDM method, variations in the input parameters were imposed that were considered to be realistic errors with regards to wind speed, measurement distances etc. The following variations were made to the estimated emissions for the three landfills:

"Wind speed $+20 \%$ ": wind speed was changed by a factor of 1.2 , corresponding to a situation in which the local wind speed during measurement was $20 \%$ higher than that recorded at the nearest weather station

"Stability class: minus one": the Pasquill-Gifford stability class was changed from, for example, class D to class C, to examine the effect of an erroneous assessment of atmospheric stability

"Urban to open": terrain type was changed from "urban", which was used in the three sites chosen, to "open" to examine the effect of this change, since determination of terrain type was not always straightforward

"Distance minus $50 \mathrm{~m}$ ": the measurement distance in the calculations was reduced by 50 metres, corresponding to a situation in which emissions from the landfill mostly occurred closer to the measurement location than assumed, which could be the case if gas leakages were unevenly distributed over the landfill surface.

\section{Results and discussion}

\subsection{Landfill emission rates and categorisation}

Table 2 presents an overview of estimates of methane emission rates and the resulting categorisation of the landfills of this study (medium and high emission sites). Of the 91 landfills surveyed, 66 were found to have emissions below $2 \mathrm{~kg} \mathrm{CH}_{4} \mathrm{~h}^{-1}$, which placed them in the low emission category and therefore meant they were not relevant for biocover implementation. At 41 of the 66 landfills, the emission was below detection (the maximum methane plume concentration was less than a signal-to-noise ratio of 3). At many of these sites, the emissions were so low that measurements had to be performed very close to the landfill in order to obtain a detectable methane concentration. The lowest modelled emission was $0.03 \mathrm{~kg} \mathrm{CH}_{4} \mathrm{~h}^{-1}$, where elevated methane concentrations of between 0.013 and 0.020 ppm $\mathrm{CH}_{4}$ were noted when traversing the downwind plume. The measurement distance in that case was relatively low (about $110 \mathrm{~m}$; defined as the distance between the location of the maximum observed downwind methane concentration to the centre of the landfill), which explains why the detection of this relatively low emission was possible. When plume measurements are performed close to a site due to detection limitations, the estimated emission rate becomes more uncertain. Even with an uncertainty of $100 \%$, a landfill with an emission of less than $1 \mathrm{~kg} \mathrm{CH}_{4} \mathrm{~h}^{-1}$ would be still be 
placed in the low emission category. In any case, landfills where elevated methane concentrations are close to detection limits would not be considered relevant for methane mitigation.

Nine landfills were classified as having high methane emissions (above $6 \mathrm{~kg} \mathrm{CH}_{4} \mathrm{~h}^{-1}$ ) and 14 landfills were classified in the "medium" category (between 2 and $6 \mathrm{~kg} \mathrm{CH}_{4} \mathrm{~h}^{-1}$ ) (Table 2). The highest emission modelled in this study was $43.1 \mathrm{~kg} \mathrm{CH}_{4} \mathrm{~h}^{-1}$, where elevated concentrations of the methane plume up to $0.031 \mathrm{ppm}^{\mathrm{CH}_{4}}$ were measured from a relatively long distance to the site $(2200 \mathrm{~m})$. For two of the 91 landfills, neighbouring sources of methane emissions were identified (adjacent landfill, biogas plant) in the screening of methane concentrations in the surrounding area, where estimation of methane emission separately from these other sources was not possible. In those cases, the emission rates were estimated to be 8.2 and $5.0 \mathrm{~kg} \mathrm{CH}_{4} \mathrm{~h}^{-1}$ respectively, implying that those landfills were potentially relevant for biocover implementation, and they were thus considered in the "high" and "medium" categories respectively even though quantification was problematic due to the nearby sources. However, unknown fractions of these estimates were methane from other sources.

The use of a vehicle to perform the measurements sets limitations on the choice of measurement location, since they have to be performed on drivable roads downwind from the sites. In some cases, the physical surroundings of the landfill provided only one option for downwind measurement. As shown in Section 3.2, the IDM method was sensitive to changes in measurement distance. Since no information was available on the spatial distribution of methane emissions from the landfill, this may provide a certain level of uncertainty with regard to the estimated methane emission rate in this case. This uncertainty is not quantifiable due to the lack of information on the spatial distribution of emissions, but can be considered higher in cases of a short distance between the landfill and measurement location, which is also suggested by the results of the sensitivity analysis in Section 3.2. In cases where the measurement distance was relatively high (such as 1-2 km), the measuring uncertainty in the estimated methane emission caused by an error in measurement distance was less likely, in view of the results of the sensitivity analysis described in Section 3.2.

From the experiences in this study, measurements performed in accordance with the relevant protocol described in Section 2.2 could be completed in approximately one hour on average for each landfill. This meant that approximately four to six landfills could be surveyed in a day, depending on the driving distance between sites. This relatively low time requirement, combined with more simple data analysis, means that the costs involved in using the quick method described are much lower - perhaps a third of the cost - than the more accurate TGD method. 
A scatter plot combined with correlation and regression analysis was used to compare methane emission rates

modelled using the IDM method and measured using the TGD method (Fig. 4). Landfills with a wide range of measured methane emissions were used in the comparison, including measured emissions near the approximate detection limit of the TGD method $\left(0.15 \mathrm{~kg} \mathrm{CH}_{4} \mathrm{~h}^{-1}\right)$ of up to approximately $500 \mathrm{~kg} \mathrm{CH}_{4} \mathrm{~h}^{-1}$ measured at a large UK landfill with a high content of organic matter. A positive correlation was found between the measurements using these two methods. Cases of overestimation and underestimation using the IDM method were seen, assuming that the TGD measurements were accurate. The coefficient of determination $\left(\mathrm{R}^{2}\right)$ of the comparison was found to be 0.965 . If the two landfills with emissions above $100 \mathrm{~kg} \mathrm{CH}_{4} \mathrm{~h}^{-1}$ are disregarded, the correlation shown in Fig. 4 is found, where emissions modelled using the IDM method equal $72 \%$ of those found using the TGD method with an $\mathrm{R}^{2}=0.765$.

The aim of developing the method for fast total methane emission estimation was to categorise a number of landfills with regards to the magnitude of methane emission (low, medium or high emission). Assuming methane emission determined by the TGD method is most accurate, a resulting category change due to a difference in the estimated emission using the IDM method would be considered an error. A difference in emission categorisation was found in just four of the 24 comparisons using the less precise IDM method. In two of these four cases, underestimation using the less precise IDM method resulted in these landfills being categorised as "medium emission" as opposed to "high emission", whereas the one case of overestimation using the IDM method resulted in this landfill being categorised as "high emission" rather than "medium emission". In all three cases the landfills would be considered relevant for implementation of biocovers and eligible for financial support for further investigations of emissions via the Biocover Initiative. Only in one case did the less precise IDM method place the landfill in the "low emission" category, whereas the TGD method would have put it in the "high emission" category, being just above the threshold between medium and high emission $\left(6 \mathrm{~kg} \mathrm{CH}_{4} \mathrm{~h}^{-1}\right)$. This is considered the most critical situation as this site would not undergo further emission investigation and therefore disqualified from biocover implementation. In the remaining 20 cases, no difference in categorisation was induced by the difference in emissions using the two methods. Thus, all in all, only one landfill site out of the 24 based on the IDM method would be incorrectly categorised in a way that would hinder further investigations and emission reduction.

The "urban to open" variation was found to have a large impact on the estimated emissions. At all three randomly chosen landfills, measurements were performed in urban environments, but changes to "open" terrain reduced the estimated emissions by approximately $80 \%$. For most of the 91 landfills surveyed in this study, the choice of terrain type was relatively straightforward, for example landfills in rural settings surrounded by open fields or by residential 
areas. The choice was more difficult in just a few cases, which included areas of mixed terrain, such as industrial areas with a few buildings and large open areas/vacant lots.

Increasing the wind speed by $20 \%$ led to an increase in the estimated emission by the same magnitude. This impact of a variation in wind speed may explain some of the differences between emissions modelled by the IDM method and the TGD method, shown in Fig. 4, since minor variations in wind speed at the site could be expected compared to records from the nearest weather service. However, a more accurate determination of wind speed at each site may improve the precision of the method, for example by setting up a local weather station to record wind sped during the plume traversing. In the context of this study, however, this adjustment would have added additional activities and thus would have contradicted the objective of providing a quick measurement method.

Changing the Pasquill-Gifford stability class significantly affected estimated emissions by up to $105 \%$. By chance, most of the measurements (64 of 91 performed in this study and 17 of the 19 historical measurements) were performed during overcast weather conditions or after sunset, where stability class D is normally used. The risk of error in this case was therefore low, but an accurate assessment of atmospheric stability was found to be important in this sensitivity test for the method in general. The comparison of emissions obtained by IDM and TGD, respectively supported that stability class D in most cases was the appropriate choice.

The "Distance minus $50 \mathrm{~m}$ " variation was found to have a high impact on the modelled emission when measuring close to the landfill, but a relatively low impact when measuring a relatively long distance away. This was expected and the measurements were taken at the greatest distance allowed by the analytical instrument, often $1000 \mathrm{~m}$ downwind the site. At low emission sites, where no measurable methane plume was observed at proper distances downwind of the site (several hundreds of meters away), measurements were taken closer to the site. The measurement distances possible using a vehicle-based measurement platform are dependent on the availability of drivable roads.

The sensitivity analysis showed overall that the IDM method, as implemented in this study, is highly sensitive to changes in model parameter values. This may explain the relatively large differences between measured methane emissions using the TGD method and the IDM method as executed in this study.

\subsection{Emission variation}

Landfill methane emissions have been shown to occur heterogeneously from landfill surfaces and other pathways and to vary in emission rate over time (Fredenslund et al., 2010; Kjeldsen, 2003; Rachor et al., 2013; Scheutz et al., 2009). When estimating the total methane emission rate, remote sensing methods such as the TGD method and 
the IDM method described in this paper have the advantage of sampling the entire methane plume emitting from the landfill, and are thus less influenced by uncertainties caused by spatial emission variability compared to conventional methods such as flux chamber measurements. With the exception of Eddy covariance, current monitoring methods measure the landfill methane emission over a relatively short timeframe and thus do not cover temporal methane emission variability. Temporal variation in emission appears to be caused by a variety of environmental factors, including changes in wind speed and barometric pressure and landfill operation (Christophersen et al., 2001; Delkash et al., 2015; Gebert and Groengroeft, 2006; Scheutz et al., 2009). To accurately assess the total methane emission from a landfill, where the objective is to estimate an average emission rate, it is therefore necessary either to measure emissions over a long period of time or to repeat measurements in order to measure emissions under varying and representative conditions. Since the methodology described in Section 2.3 results in estimates of emission rates based on measurements over a short period of time $(<1$ hour $)$, a significant difference between a single modelled emission rate and the average emission over a longer period can be expected. As described in Sections 2.3 and 3.1, the methodology was essentially used to remove a large number of the landfills surveyed from consideration and thus from further investigation for methane mitigation efforts. When setting the threshold for this removal ( $2 \mathrm{~kg} \mathrm{CH}_{4} \mathrm{~h}^{-1}$ in this case), it should be taken into account that the estimates of methane emissions based on IDM are subject to considerable measurement uncertainty (see Section 3.2) and emission variation. A worst-case scenario could be a landfill where the emission from a site is estimated at $1.9 \mathrm{~kg} \mathrm{CH}_{4} \mathrm{~h}^{-1}$, but the average emission over a longer period of time from the site is $100 \%$ greater $\left(3.8 \mathrm{~kg} \mathrm{CH}_{4} \mathrm{~h}^{-1}\right)$. In that case, removal of the landfill from consideration would be acceptable since the "real" emission is still relatively low, and thus the site is of low interest for biocover implementation. Finally, it should be noted that all medium and high-emission landfills would undergo further emission investigations, with methane emissions quantified using TDG before and after the installation of biocovers.

\section{Conclusions}

A semi-quantitative methane emission quantification method based on downwind measurements of methane concentrations combined with a dispersion model (IDM) was developed in order to be able to survey a relatively large number of landfills. The method was found to be considerably quicker to use, and therefore more cost-effective, than more precise methods such as the tracer gas dispersion (TGD) method. The method was used to categorise 91 landfills based on the magnitude of their methane emissions. A sensitivity analysis of the IDM method showed that the method is highly sensitive to variations in model parameters, and the uncertainty in the method is estimated to be considerably 
higher than other options such as the TGD method, where dispersion is measured using a gaseous tracer release. The developed method based on IDM was found to be useful for fast landfill methane screenings and suitable for providing a first estimation of methane emissions, which can then be used to prioritise mitigation actions. However, the IDM method cannot replace more accurate approaches such as the TGD method, which are needed for documenting emission reduction efficiencies.

\section{Acknowledgement}

This work was supported by the Danish Environmental Protection Agency.

\section{References}

Bogner, J., Pipatti, R., Hashimoto, S., Diaz, C., Mareckova, K., Diaz, L., Kjeldsen, P., Monni, S., Faaij, A., Qingxian, G., Tianzhu, Z., Mohammed, A.A., Sutamihardja, R.T.M., Gregory, R., 2008. Mitigation of global greenhouse gas emissions from waste: Conclusions and strategies from the Intergovernmental Panel on Climate Change (IPCC) Fourth Assessment Report. Working Group III (Mitigation). Waste Manag. Res. 26, 11-32. doi:10.1177/0734242X07088433

Briggs, G.A., 1973. Diffusion Estimation for Small Emissions. NOAA, Laboratory, United States. Air Resources Atmospheric Turbulence and Diffusion.

Christophersen, M., Kjeldsen, P., Holst, H., Chanton, J., 2001. Lateral gas transport in soil adjacent to an old landfill: factors governing emissions and methane oxidation. Waste Manag. Res. 19, 595-612. doi:10.1177/0734242X0101900616

Danish Environmental Protection Agency, 2016a. Tilskudsordning for biocover [WWW Document]. URL http://mst.dk/virksomhed-myndighed/affald/deponering/biocover-tilskudsordning/ (accessed 3.13.17).

Danish Environmental Protection Agency, 2016b. Biocover guidelines [WWW Document]. URL http://mst.dk/virksomhed-myndighed/affald/deponering/biocover-tilskudsordning/afrapportering-ogdokumentationskrav/

De Visscher, A., 2014. Chapter 6: Gaussian Dispersion Modeling: An In-Depth Primer. Air Dispers. Model. Found. Appl. 141-200.

Delkash, M., Zhou, B., Han, B., Chow, F.K., Rella, C.W., Imhoff, P.T., 2015. Short-term landfill methane emissions dependency on wind. Waste Manag. 55, 288-298. doi:10.1016/j.wasman.2016.02.009 
Delre, A., Mønster, J., Scheutz, C., 2017. Greenhouse gas emission quantification from wastewater treatment plants, using a tracer gas dispersion method. Sci. Total Environ. 605-606, 258-268. doi:10.1016/j.scitotenv.2017.06.177

Foster-Wittig, T.A., Thoma, E.D., Green, R.B., Hater, G.R., Swan, N.D., Chanton, J.P., 2015. Development of a mobile tracer correlation method for assessment of air emissions from landfills and other area sources. Atmos. Environ. 102, 323-330. doi:10.1016/j.atmosenv.2014.12.008

Fredenslund, A.M., Scheutz, C., Kjeldsen, P., 2010. Tracer method to measure landfill gas emissions from leachate collection systems. Waste Manag. 30, 2146-2152. doi:10.1016/j.wasman.2010.03.013

Gebert, J., Groengroeft, A., 2006. Passive landfill gas emission - Influence of atmospheric pressure and implications for the operation of methane-oxidising biofilters. Waste Manag. 26, 245-251. doi:10.1016/j.wasman.2005.01.022

Goldsmith, C.D., Chanton, J., Abichou, T., Swan, N., Green, R., Hater, G., 2012. Methane emissions from 20 landfills across the United States using vertical radial plume mapping. J. Air Waste Manage. Assoc. 62, 183-197. doi:10.1080/10473289.2011.639480

Kjeldsen, P., 2003. Relating landfill gas emissions to atmospheric pressure using numerical modelling and state-space analysis $356-366$.

Lou, X.F., Nair, J., 2009. The impact of landfilling and composting on greenhouse gas emissions - A review. Bioresour. Technol. 100, 3792-3798. doi:10.1016/j.biortech.2008.12.006

Mohan, M., Siddiqui, T. a, 1997. an Evaluation of Dispersion Coefficients for Use in Air. Boundary-Layer Meteorol. 177-206. doi:Doi 10.1023/A:1000317704452

Mønster, J., Samuelsson, J., Kjeldsen, P., Scheutz, C., 2015. Quantification of methane emissions from 15 Danish landfills using the mobile tracer dispersion method. Waste Manag. 35, 177-186. doi:10.1016/j.wasman.2014.09.006

Mønster, J.G., Samuelsson, J., Kjeldsen, P., Rella, C.W., Scheutz, C., 2014. Quantifying methane emission from fugitive sources by combining tracer release and downwind measurements - A sensitivity analysis based on multiple field surveys. Waste Manag. 34, 1416-1428. doi:10.1016/j.wasman.2014.03.025

Rachor, I.M., Gebert, J., Gröngröft, A., Pfeiffer, E.M., 2013. Variability of methane emissions from an old landfill over different time-scales. Eur. J. Soil Sci. 64, 16-26. doi:10.1111/ejss.12004

Scheutz, C., Fredenslund, A.M., Chanton, J., Pedersen, G.B., Kjeldsen, P., 2011. Mitigation of methane emission from Fakse landfill using a biowindow system. Waste Manag. 31, 1018-1028. doi:10.1016/j.wasman.2011.01.024

Scheutz, C., Kjeldsen, P., Bogner, J.E., De Visscher, A., Gebert, J., Hilger, H. a, Huber-Humer, M., Spokas, K., 2009. 

Res. 27, 409-455. doi:10.1177/0734242X09339325

3 Scheutz, C., Pedersen, R.B., Petersen, P.H., Jørgensen, J.H.B., Ucendo, I.M.B., Mønster, J.G., Samuelsson, J., Kjeldsen, P., 2014. Mitigation of methane emission from an old unlined landfill in Klintholm, Denmark using a passive biocover system. Waste Manag. 34, 1179-1190. doi:10.1016/j.wasman.2014.03.015

6 Tværministeriel arbejdsgruppe, 2013. Virkemiddelkatalog - Potentialer og omkostninger for klimatiltag.

7 Yoshida, H., Mønster, J., Scheutz, C., 2014. Plant-integrated measurement of greenhouse gas emissions from a municipal wastewater treatment plant. Water Res. 61, 108-118. doi:10.1016/j.watres.2014.05.014

9 


\section{TABLES}

2

3 Table 1. Briggs formula for estimating dispersion coefficients (Briggs, 1973; Mohan and Siddiqui, 1997). X signifies 4 the distance to the source of emission in metres $(\mathrm{m})$.

\begin{tabular}{lll}
\hline Pasquill-Gifford stability class & $\sigma_{\mathrm{y}}(\mathrm{m})$ & $\sigma_{\mathrm{x}}(\mathrm{m})$ \\
\hline Open-country terrain & & \\
$\mathrm{A}$ & $0.22 \cdot \mathrm{x} \cdot(1+0.0001 \cdot \mathrm{x})^{-1 / 2}$ & $0.20 \cdot \mathrm{x}$ \\
$\mathrm{B}$ & $0.16 \cdot \mathrm{x} \cdot(1+0.0001 \cdot \mathrm{x})^{-1 / 2}$ & $0.12 \cdot \mathrm{x}$ \\
$\mathrm{C}$ & $0.11 \cdot \mathrm{x} \cdot(1+0.0001 \cdot \mathrm{x})^{-1 / 2}$ & $0.08 \cdot \mathrm{x} \cdot(1+0.0002 \cdot \mathrm{x})^{-1 / 2}$ \\
$\mathrm{D}$ & $0.08 \cdot \mathrm{x} \cdot(1+0.0001 \cdot \mathrm{x})^{-1 / 2}$ & $0.06 \cdot \mathrm{x} \cdot(1+0.0015 \cdot \mathrm{x})^{-1 / 2}$ \\
$\mathrm{E}$ & $0.06 \cdot \mathrm{x} \cdot(1+0.0001 \cdot \mathrm{x})^{-1 / 2}$ & $0.03 \cdot \mathrm{x} \cdot(1+0.0003 \cdot \mathrm{x} \cdot)^{-1 / 2}$ \\
$\mathrm{~F}$ & $0.04 \cdot \mathrm{x} \cdot(1+0.0001 \cdot \mathrm{x} \cdot)^{-1 / 2}$ & $0.016 \cdot \mathrm{x} \cdot(1+0.0003 \cdot \mathrm{x})^{-1 / 2}$ \\
Urban conditions & & \\
A-B & $0.32 \cdot \mathrm{x} \cdot(1+0.0004 \cdot \mathrm{x})^{-1 / 2}$ & $0.24 \cdot \mathrm{x}(1+001 \cdot \mathrm{x})^{-1 / 2}$ \\
$\mathrm{C}$ & $0.22 \cdot \mathrm{x} \cdot(1+0.0004 \cdot \mathrm{x})^{-1 / 2}$ & $0.20 \cdot \mathrm{x}$ \\
$\mathrm{D}$ & $0.16 \cdot \mathrm{x} \cdot(1+0.0004 \cdot \mathrm{x})^{-1 / 2}$ & $0.14 \mathrm{x}(1+0.0003 \cdot \mathrm{x})^{-1 / 2}$ \\
E-F & $0.11 \cdot \mathrm{x} \cdot(1+0.0004 \cdot \mathrm{x})^{-1 / 2}$ & $0.08 \cdot \mathrm{x}(1+0.00015 \cdot \mathrm{x})^{-1 / 2}$ \\
\hline
\end{tabular}


1 Table 2. Overview of estimated methane emissions and atmospheric conditions for landfills where emission rate 2 estimations using the described method were possible.

\begin{tabular}{|c|c|c|c|c|c|}
\hline $\begin{array}{l}\text { Site } \\
\text { number }\end{array}$ & $\begin{array}{l}\text { Pasquill-Gifford } \\
\text { stability class, } \\
\text { terrain type }\end{array}$ & $\begin{array}{l}\text { Atmospheric } \\
\text { pressure (mbar), } \\
\text { tendency }\end{array}$ & $\begin{array}{l}\text { Average } \\
\text { peak height } \\
\left(\mathrm{ppm} \mathrm{CH}_{4}\right)^{\mathrm{a}}\end{array}$ & $\begin{array}{l}\text { Modelled } \mathrm{CH}_{4} \\
\text { emission }{ }^{\mathrm{b}}\left(\mathrm{kg} \mathrm{CH}_{4} \mathrm{~h}^{-1}\right) \\
\text { and sample standard } \\
\text { deviation }\end{array}$ & $\begin{array}{l}\text { Detection limit }^{\mathrm{c}} \\
\left(\mathrm{kg} \mathrm{CH}_{4} \mathrm{~h}^{-1}\right)\end{array}$ \\
\hline \multicolumn{6}{|l|}{$\begin{array}{l}\text { High } \\
\text { emission }\end{array}$} \\
\hline 1 & B, open & 1019, decreasing & 0.136 & $16.8(3.4)$ & 0.18 \\
\hline 2 & B, open & 1015, stable & 0.052 & $14.6(9.7)$ & 0.50 \\
\hline 3 & $\mathrm{D}$, urban & 1002, stable & 0.037 & $16.8(3.5)$ & 0.67 \\
\hline 4 & $\mathrm{D}$, urban & 1011, decreasing & 0.177 & $25.9(7.3)$ & 0.21 \\
\hline 5 & $\mathrm{C}$, open & 1016, stable & 0.803 & $19.4(10.5)$ & 0.04 \\
\hline 6 & D, urban & 1008 , stable & 0.018 & $8.7(2.3)$ & 0.73 \\
\hline 7 & D, urban & 1007, decreasing & 0.680 & $18.3(9.8)$ & 0.38 \\
\hline 8 & $\mathrm{C}$, urban & 1017, increasing & 0.750 & $19.9(5.7)$ & 0.04 \\
\hline 9 & $\mathrm{D}$, urban & 1009, stable & 0.056 & $30.4(11.5)$ & 0.01 \\
\hline \multicolumn{6}{|l|}{$\begin{array}{l}\text { Medium } \\
\text { emission }\end{array}$} \\
\hline 10 & $\mathrm{D}$, open & 1022 , stable & 0.334 & $3.1(1.6)$ & 0.01 \\
\hline 11 & $\mathrm{C}$, urban & 1022, decreasing & 0.012 & $2.4(0.5)$ & 0.28 \\
\hline 12 & $\mathrm{C}$, urban & 1022, decreasing & 0.034 & $3.1(1.7)$ & 0.13 \\
\hline 13 & $\mathrm{D}$, open & 1020, decreasing & 0.032 & $3.4(1.6)$ & 0.09 \\
\hline 14 & D, open & 1017, increasing & 0.030 & $2.3(0.4)$ & 0.11 \\
\hline 15 & $\mathrm{C}$, urban & 1012, decreasing & 0.041 & $2.2(0.5)$ & 0.08 \\
\hline 16 & $\mathrm{D}$, open & 1014, stable & 0.008 & $2.9(0.3)$ & 0.52 \\
\hline 17 & $\mathrm{D}$, open & 1014, stable & 0.126 & $3.9(1.8)$ & 0.11 \\
\hline 18 & $\mathrm{D}$, open & 1015, stable & 0.013 & $2.6(0.8)$ & 0.31 \\
\hline 19 & $\mathrm{D}$, open & 1015, decreasing & 0.025 & $3.6(0.9)$ & 0.11 \\
\hline 20 & $\mathrm{C}$, open & 1013, stable & 0.026 & $2.6(0.8)$ & 0.14 \\
\hline 21 & $\mathrm{D}$, urban & 1017 , increasing & 0.750 & $2.3(0.9)$ & 0.18 \\
\hline 22 & D, urban & 1013, increasing & 0.020 & $5.6(1.6)$ & 0.40 \\
\hline 23 & $\mathrm{D}$, open & 1010, stable & 0.523 & $5.6(1.4)$ & 0.02 \\
\hline \multicolumn{6}{|l|}{ Low } \\
\hline emission & & & & & \\
\hline 24 & $\mathrm{D}$, open & 1022, stable & 0.030 & $1.3(0.4)$ & 0.06 \\
\hline 25 & $\mathrm{D}$, open & 1002, decreasing & 0.019 & $0.6(0.2)$ & 0.05 \\
\hline 26 & $\mathrm{D}$, urban & 1015 , stable & 0.040 & $1.1(0.3)$ & 0.04 \\
\hline 27 & $\mathrm{D}$, open & 1013, stable & 0.030 & $0.1(0.1)$ & 0.01 \\
\hline 28 & $\mathrm{D}$, open & 1006, decreasing & 0.025 & $0.2(0.1)$ & 0.01 \\
\hline 29 & $\mathrm{D}$, open & 1013, increasing & 0.028 & $0.8(0.1)$ & 0.04 \\
\hline 30 & $\mathrm{D}$, urban & 1013, decreasing & 0.006 & $0.03(0.01)$ & 0.01 \\
\hline 31 & $\mathrm{C}$, open & 1016, stable & 0.027 & $0.1(0.02)$ & 0.01 \\
\hline 32 & $\mathrm{D}$, open & 1014 , increasing & 0.012 & $1.1(0.3)$ & 0.13 \\
\hline 33 & $\mathrm{D}$, open & 1018, decreasing & 0.016 & $0.03(0.01)$ & 0.003 \\
\hline 34 & $\mathrm{D}$, open & 1014, stable & 0.021 & $1.6(0.6)$ & 0.11 \\
\hline 35 & $\mathrm{D}$, open & 1018, decreasing & 0.012 & $0.6(0.1)$ & 0.08 \\
\hline 36 & $\mathrm{D}$, open & 1007 , stable & 0.028 & $1.7(0.1)$ & 0.09 \\
\hline 37 & $\mathrm{D}$, urban & 1007, stable & 0.081 & $1.2(0.3)$ & 0.02 \\
\hline 38 & $\mathrm{D}$, open & 1015, decreasing & 0.021 & $0.05(0.01)$ & 0.003 \\
\hline $39+40^{\mathrm{d}}$ & $\mathrm{D}$, open & 1008 , decreasing & 0.027 & $0.5(0.1)$ & 0.03 \\
\hline 41 & $\mathrm{D}$, open & 1013, decreasing & 0.015 & $1.2(-)^{\mathrm{e}}$ & 0.12 \\
\hline 42 & $\mathrm{D}$, urban & 1013, decreasing & 0.007 & $0.8(-)^{\mathrm{e}}$ & 0.18 \\
\hline 43 & $\mathrm{D}$, urban & 1016 , increasing & 0.026 & $1.8(0.2)$ & 0.10 \\
\hline 44 & $\mathrm{D}$, open & 1016, increasing & 0.009 & $0.4(0.1)$ & 0.07 \\
\hline $45+46^{\mathrm{d}}$ & $\mathrm{D}$, open & 1009, stable & 0.247 & $0.7(0.7)$ & 0.03 \\
\hline 47 & $\mathrm{D}$, open & 1009, stable & 0.056 & $0.5(0.1)$ & 0.01 \\
\hline 48 & $\mathrm{D}$, open & 1014, decreasing & 0.011 & $0.3(0.2)$ & 0.02 \\
\hline
\end{tabular}


$1 \quad{ }^{\mathrm{a}}$ Peak height of Gaussian fit - average of performed plume traverses.

$2{ }^{\mathrm{b}}$ Average of performed plume traverses.

3 c Determined as described in Section 2.3.

4 d Two adjacent landfills, from where a single plume was detected.

$5{ }^{\mathrm{e}}$ Single, successful plume traverse due to low signal (see peak height). 
1 Table 3. Sensitivity analysis of the inverse dispersion model method applied to three landfills. Listed values are total 2 methane emissions given in the unit $\mathrm{kg} \mathrm{CH}_{4} \mathrm{~h}^{-1}$. For the variations, relative changes in estimated emissions compared to 3 the normal scenario are listed in brackets. Relative change $=100 \% *$ (variation-normal)/normal.

\begin{tabular}{llllll}
\hline Landfill & Normal & $\begin{array}{l}\text { "Wind speed }+20 \\
\% "\end{array}$ & $\begin{array}{l}\text { "Stability class } \\
\text { minus one" }\end{array}$ & "Urban to open" & "Distance minus \\
50 m"
\end{tabular}

4 
2

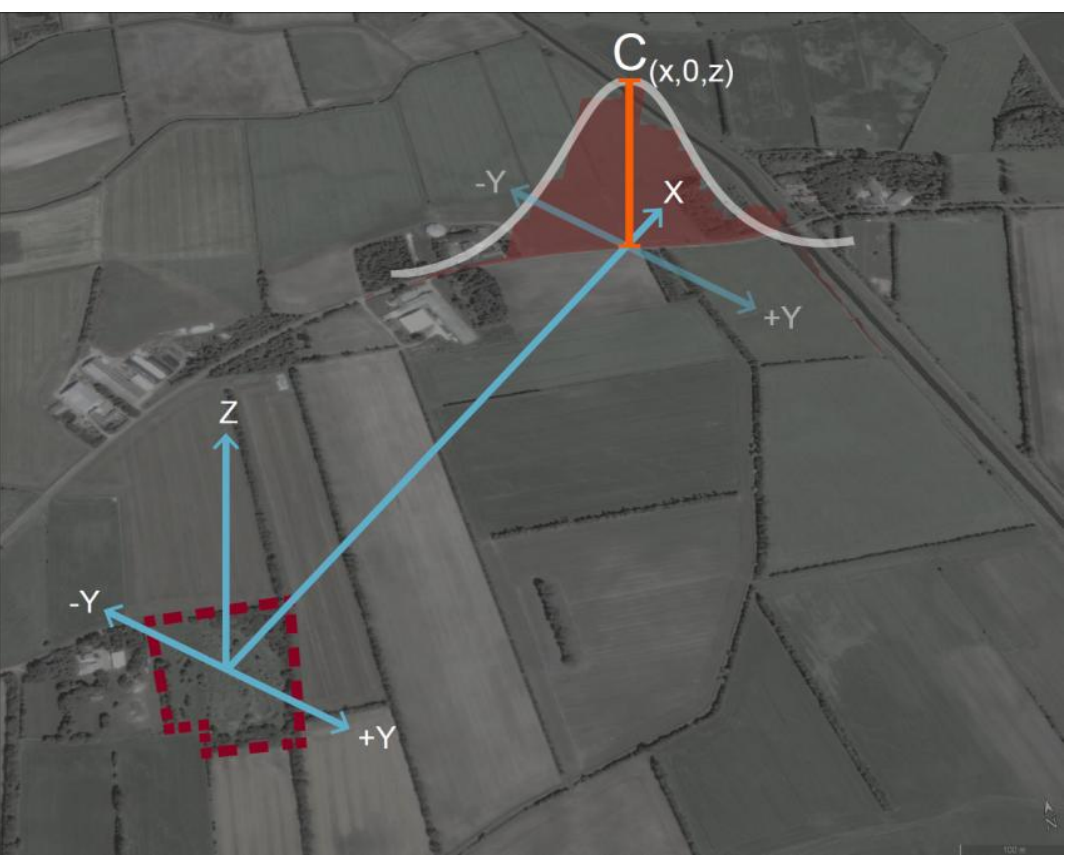

3

4 Fig. 1. Dispersion model applied to the measured downwind methane plume from a landfill. The height of the red curve 5 is proportional to measured methane concentrations above background level during a traverse of the downwind plume.

6 


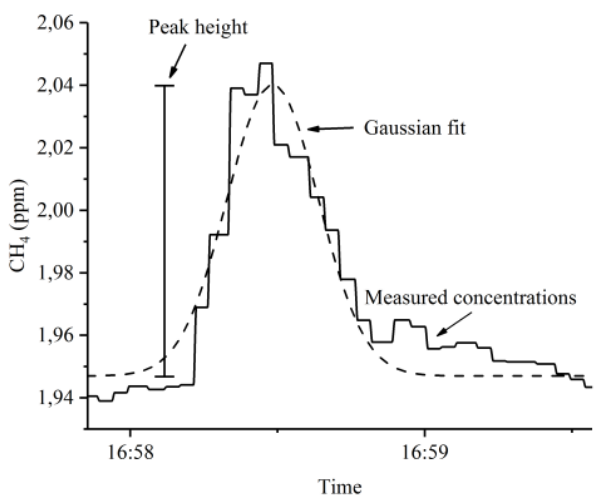

1

2 Fig. 2. Gaussian fit of measured downwind methane concentrations to determine peak height (maximum methane 3 concentration above background).

4 


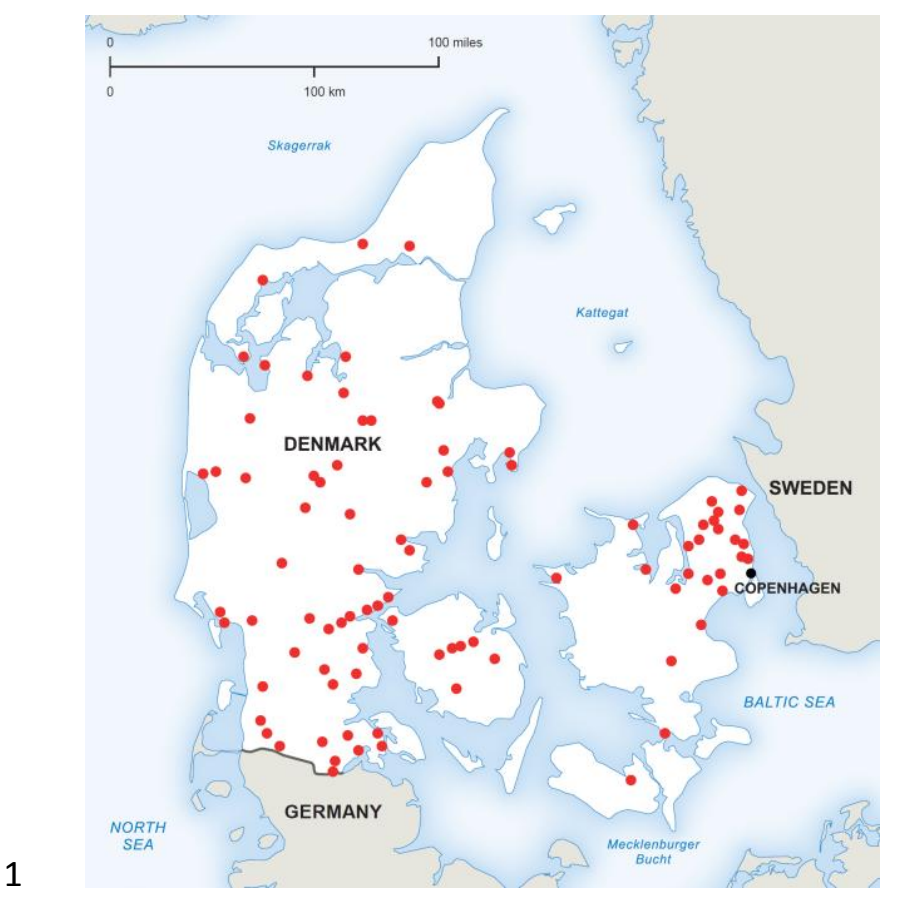

2 Fig. 3. Locations of the landfills included in this study. 


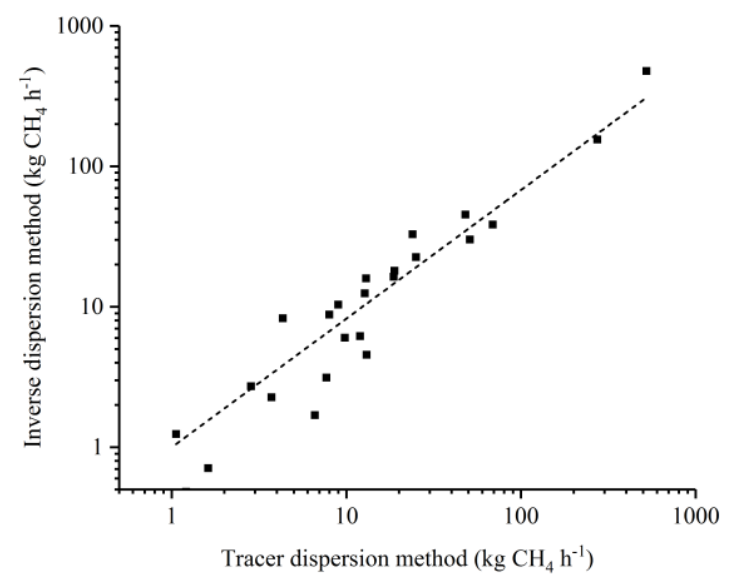

1

2 Fig. 4. Comparison of total methane emission rate estimates from 24 landfills using the IDM and TGD methods 3 simultaneously. 